\title{
Aqueous particle generation with a 3D printed nebulizer
}

\author{
Michael Rösch $^{1,2}$ and Daniel J. Cziczo ${ }^{1,3,4}$ \\ ${ }^{1}$ Department of Earth, Atmospheric \& Planetary Sciences, Massachusetts Institute of Technology, \\ Cambridge, 02139, USA \\ ${ }^{2}$ Department of Environmental Systems Science, Eidgenössische Technische Hochschule - ETH, Zurich, 8092, Switzerland \\ ${ }^{3}$ Department of Civil Environmental Engineering, Massachusetts Institute of Technology, Cambridge, 02139, USA \\ ${ }^{4}$ Department of Earth, Atmospheric and Planetary Sciences, Purdue University, West Lafayette, IN 47907, USA
}

Correspondence: Michael Roesch (michael.roesch@env.ethz.ch)

Received: 22 April 2020 - Discussion started: 9 June 2020

Revised: 6 November 2020 - Accepted: 6 November 2020 - Published: 16 December 2020

\begin{abstract}
In this study, we describe the design and testing of a high-output-stability, constant-liquid-feed nebulizer using the Venturi principle to generate liquid particles from solutions. This atomizer, the PRinted drOpleT Generator (PROTeGE), was manufactured using stereolithography (SLA) printing. Different concentrations of ammonium sulfate solutions were used to characterize the size and number concentration of the generated particles. A comparison of a 3D printed $0.5 \mathrm{~mm}$ orifice against a commercially available $0.5 \mathrm{~mm}$ brass orifice using the same ammonium sulfate solution was also performed. The particle number concentration generated with the printed orifice was higher, by $\sim \times 2$, than the particle number concentration generated with the brass orifice.

PROTeGE is also capable of dispersing polystyrene latex (PSL) spheres for calibration purposes. The particle number concentrations obtained in this study ranged from $\sim 10000 \mathrm{~cm}^{-3}$ for $0.75 \mu \mathrm{m}$ to $\sim 100 \mathrm{~cm}^{-3}$ for $5.0 \mu \mathrm{m}$ PSL particles with a dependence on the concentration of the dispersed solution. For the different concentrated ammonium sulfate solutions particle number concentrations from $\sim 14000 \mathrm{~cm}^{-3}$ for $0.1 \mathrm{~g} \mathrm{~L}^{-1}$ to $7600 \mathrm{~cm}^{-3}$ for $5.0 \mathrm{~g} \mathrm{~L}^{-1}$ were measured. An additional measurement with a scanning electrical mobility system (SEMS) was performed for the $0.6 \mathrm{~g} \mathrm{~L}^{-1}$ solution to measure particles in the size range of 10 to $1000 \mathrm{~nm}$. The generated particle number size distributions (PNSDs) showed a maximum at $50 \mathrm{~nm}$ with particle number concentrations of $\sim 40000 \mathrm{~cm}^{-3}$. PROTeGE is easy to manufacture and operate, low in maintenance, and cost-effective for laboratory and field generation of particles from aqueous media in a size range of 10 to $5000 \mathrm{~nm}$.
\end{abstract}

\section{Introduction}

Reliable and cost-effective particle generation methods are necessary for applications where a well-defined mono- or polydisperse particle concentration and size are required. High concentrations of monodisperse aerosol particles (> $10^{6}$ particles $\mathrm{cm}^{-3}$ ) in the nanometer to micrometer diameter size range can be created by instruments utilizing vapor condensation and electrospray techniques. Similar concentrations and size ranges of aerosol particles can be produced from bulk solutions using a variety of instruments such as vibrating-orifice aerosol generators and ultrasonic nebulizers. Another common technique used to generate liquid aerosol particles is by pressurized-air nebulization. In this method, compressed air is utilized to shatter a solution into small aerosol droplets with a specific size distribution (Swiderska-Kowalczyk et al., 1997). Pressurized-air nebulizers have been used in numerous studies which require the generation of aqueous aerosol particles. For example, Wang et al. (2019) used a nebulizer to create ammonium sulfate seed particles in cloud droplet activation studies. Kong et al. (2018) created aqueous aerosol particles used to study deliquescence and ice nucleation in sea salt particles. These are two of many studies focused on the influence of aerosol particles in the Earth's atmosphere. Pressurized-air nebulizers are also used in pharmaceutical applications to produce nanometer-sized drug particles with a specific size distribution (Eerikainen et al., 2003). It is clear that the pressurizedair nebulizer is a ubiquitous instrument for studies or applications requiring aqueous aerosol particle generation. Although effective, commercial particle generation instruments may 
(a)

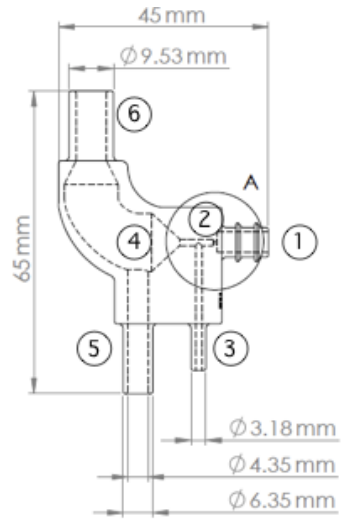

(c)

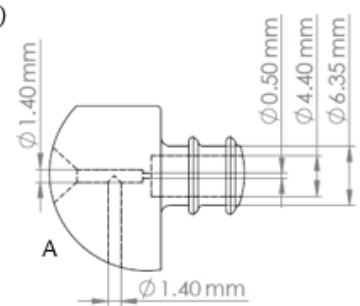

(b)

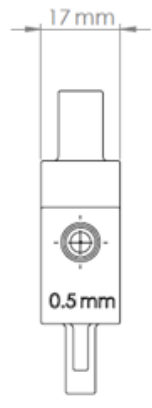

(d)

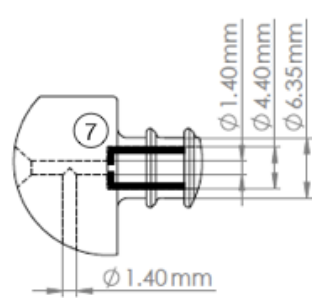

Figure 1. Dimensioned drawings of PROTeGE: (a) side view; (b) front view; (c) detailed view of the inlet section with the printed $0.5 \mathrm{~mm}$ orifice; (d) detailed view of the inlet section with the exchangeable nozzle/orifice. PROTeGE consists of (1) a pressurizedair inlet, (2) a printed $0.5 \mathrm{~mm}$ orifice, (3) a liquid feed inlet, (4) a central impaction chamber, (5) the drain outlet, (6) an aerosol outlet, and an optional (7) exchangeable orifice.

not be economically feasible for all research and teaching institutions wishing to perform these types of experiments.

Advances in 3D printing have made it possible to rapidly fabricate high-resolution (micrometer-scale) devices. Stereolithography, a form of 3D printing technology, creates objects in layers through the use of photopolymerization. In conjunction with computer-aided design (CAD) or computer-aided manufacturing (CAM) software, an ultraviolet (UV) laser is used to trace a pre-programmed design onto the surface of a photopolymer contained in a vat. The resin is photochemically solidified and forms a single layer of the desired object. The Form 2 stereolithography (SLA) 3D printer (Formlabs, Inc.), used in this work, is capable of creating objects with a layer thickness of $25 \mu \mathrm{m}$.

The Form 2 was previously used to fabricate PRIZE, a compact fluidized bed aerosol generator (Roesch et al., 2017). It was found that PRIZE was able to successfully disperse aerosol particles from dry material without creating artifact particles (particles generated from the material used to fabricate the generator). The impetus for this study, similar to the study presented in Roesch et al. (2017), was to fabricate a low-cost constant-pressure nebulizer, using a SLA 3D printer, PROTeGE. In the following two sections we describe how PROTeGE is designed and manufactured. The experimental setup and performance tests using different PSL

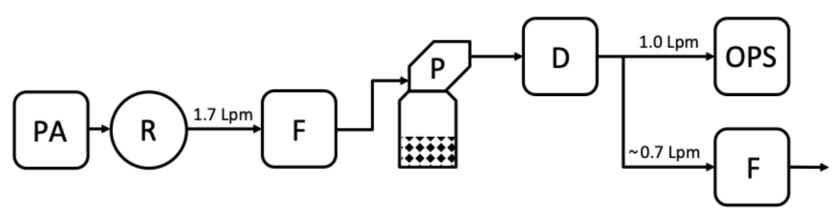

Figure 2. Schematic of the experimental setup used in this study. A dry pressurized-air flow (PA) was passed through a rotameter (R) to control the flow rate and a filter (F) upstream of PROTeGE (P). Generated droplets were dried with silica gel (D) before the flow of particles was directed into an OPS with excess flow discarded through a filter $(\mathrm{F})$.

and ammonium sulfate solutions are discussed. Three types of experiments were conducted to demonstrate the performance of PROTeGE: (1) an aerosol production experiment using four different sizes of PSL particles (Polysciences Inc., NIST traceable) ranging from 0.75 to $5.0 \mu \mathrm{m}$, (2) experiments where different concentrations of ammonium sulfate solutions were dispersed and monitored over time with an optical particle sizer (OPS, model 3330, TSI Inc.) and for the $0.6 \mathrm{~g} \mathrm{~L}^{-1}$ also with a scanning electrical mobility system (SEMS) (BMI Inc.) and (3) an experiment comparing the performance of a printed $0.5 \mathrm{~mm}$ orifice to a $0.5 \mathrm{~mm}$ commercial brass orifice using the same ammonium sulfate solution of $0.6 \mathrm{~g} \mathrm{~L}^{-1}$.

\section{Methods}

\subsection{Design}

PROTeGE was designed using a CAD program (Solidworks 2015, Dassault Systems). There are two versions: the first is printed as a single part including a $0.5 \mathrm{~mm}$ diameter orifice (Fig. 1), while the second, featuring the same inner and outer dimensions, has an exchangeable nozzle to use various machined orifice diameters. The $0.5 \mathrm{~mm}(0.02 \mathrm{in})$ orifice used in the comparison is a commercially available brass nozzle (part number 2943T887, McMaster-Carr) that is threaded into the pressurized-air inlet of PROTeGE (Fig. 1d). This modular feature enables rapid exchange of nozzles with a different orifice diameter using the same printed unit. In contrast, the exclusively printed version of PROTeGE has a fixed orifice diameter for continuous and simple operation. Both versions are based on the generator designs of May (1973) and Liu and Lee (1975). Unlike the repurposing of existing nebulizers built for other uses, such as medical applications (Reisner et al., 2001), PROTeGE was designed specifically for research applications, e.g., instrument calibration and particle generation, similar to other custom-built nebulizers (Wex et al., 2015). In contrast to other generation systems, which are typically machined, PROTeGE is made from photopolymer resin (e.g., FLGPCL02, Formlabs Inc.), weighs only $\sim 50 \mathrm{~g}$ and can therefore feature smaller overall dimensions. 

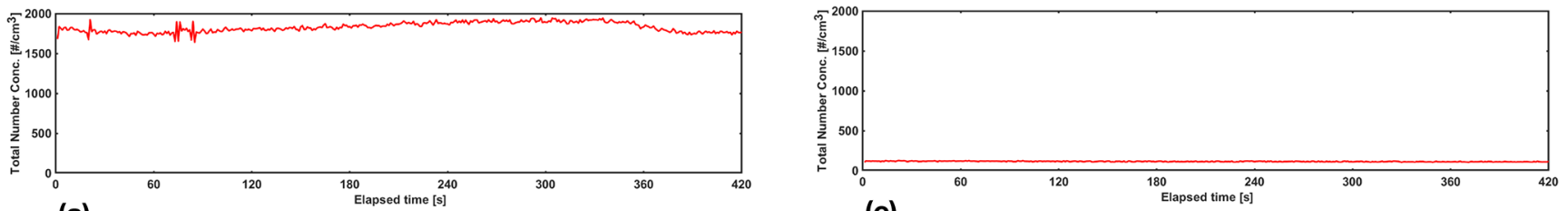

(a)

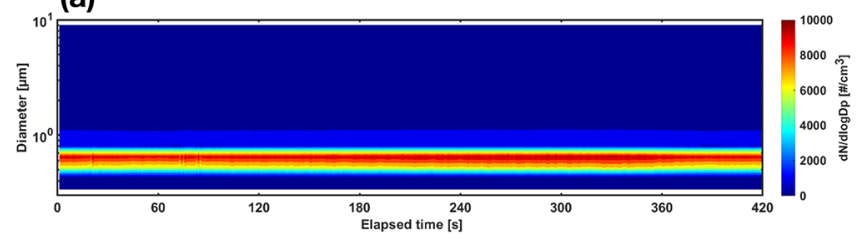

(c)
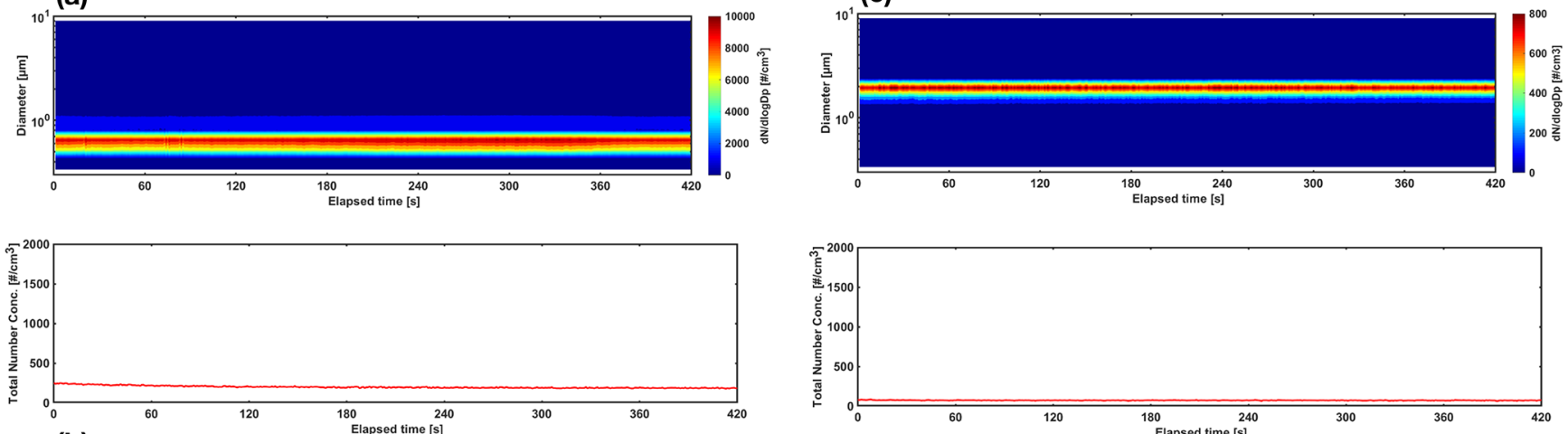

(b)
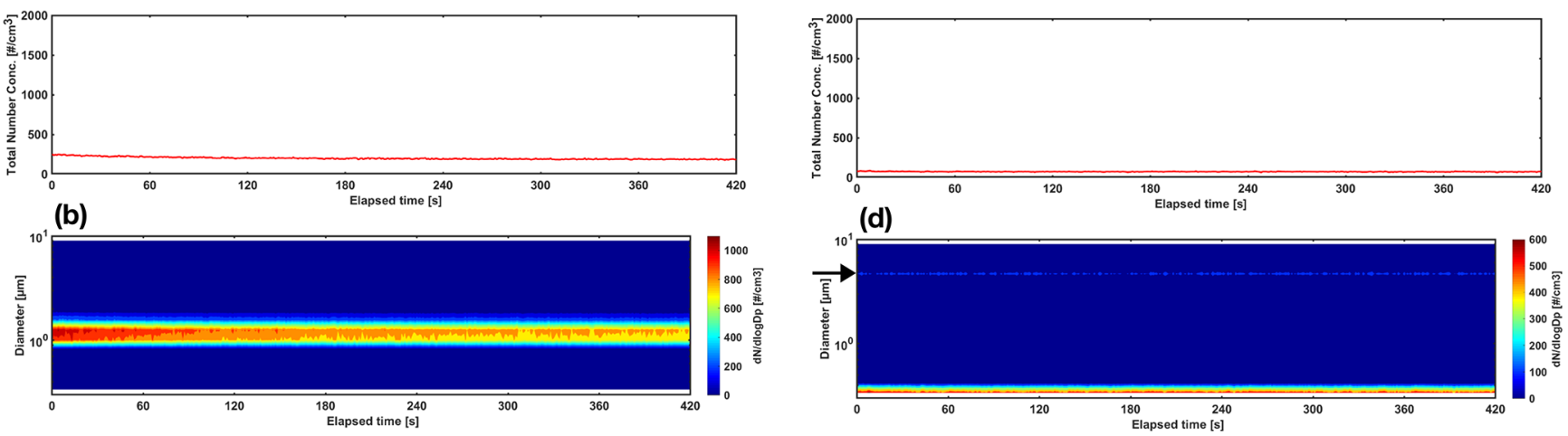

Figure 3. Total particle number concentrations and particle number size distributions as function of time for different sized polystyrene latex spheres generated with PROTeGE and detected by the OPS: (a) $0.75 \mu \mathrm{m}$, (b) $1.5 \mu \mathrm{m}$, (c) $2.0 \mu \mathrm{m}$ and (d) $5.0 \mu \mathrm{m}$ where the black arrow denotes the PSL particle size and the small particles represent atomized matrix material (see text for details).

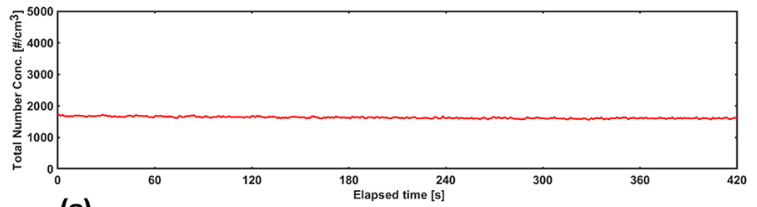

(a)
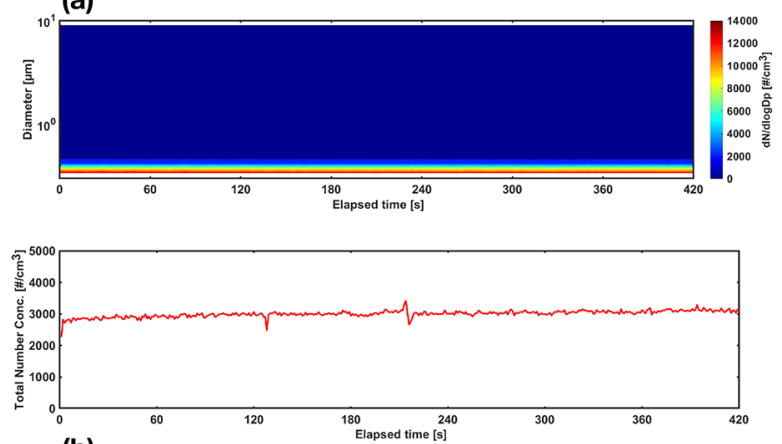

(b)

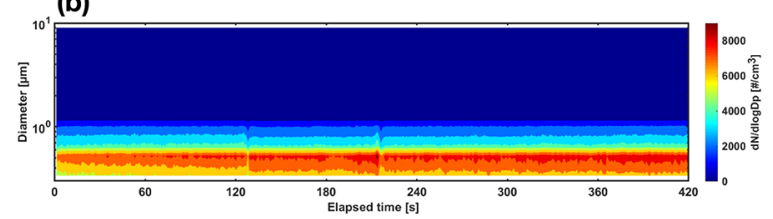

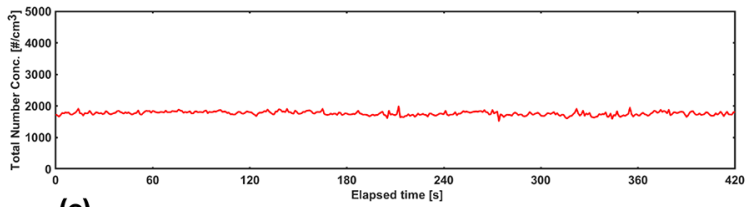

(c)

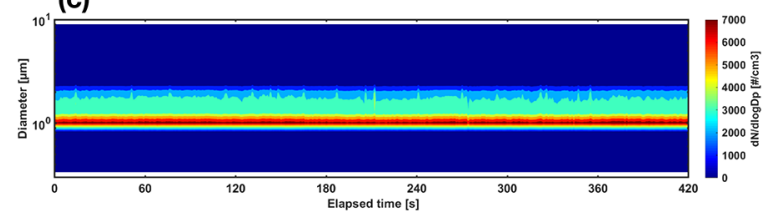

(d)

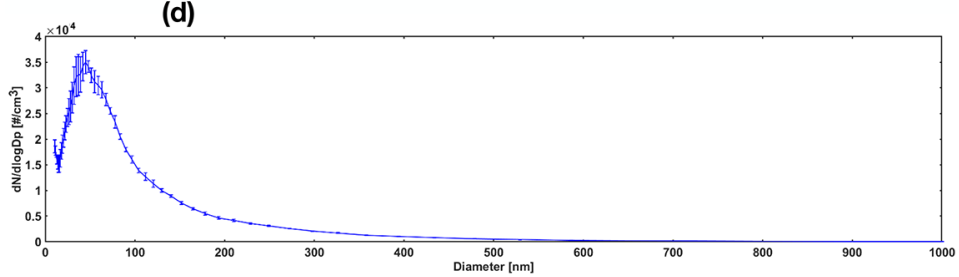

Figure 4. Total particle number concentrations and particle number size distributions as a function of time of aqueous ammonium sulfate particles: (a) $0.1 \mathrm{~g} \mathrm{~L}^{-1}$, (b) $0.6 \mathrm{~g} \mathrm{~L}^{-1}$, (c) $5.0 \mathrm{~g} \mathrm{~L}^{-1}$. (d) Average particle number size distribution from 10 to $1000 \mathrm{~nm}$ measured with the SEMS for aqueous ammonium sulfate particles of $0.6 \mathrm{~g} \mathrm{~L}^{-1}$. 

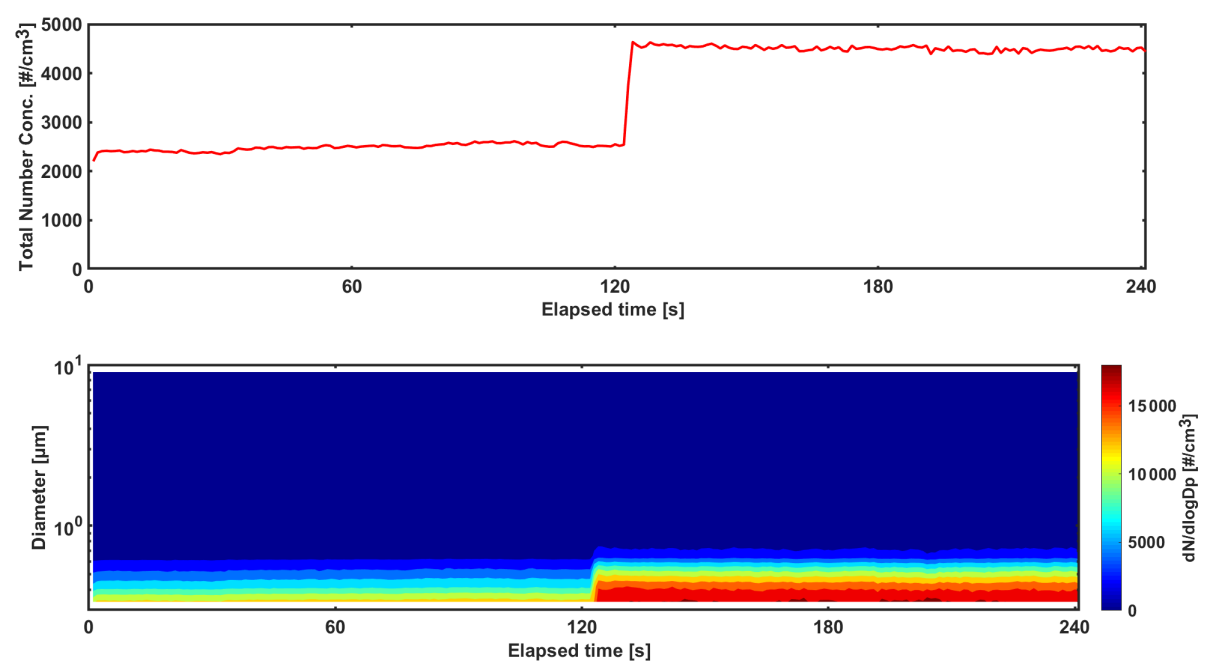

Figure 5. Total particle number concentrations and particle number size distributions as a function of time of aqueous ammonium sulfate particles at $0.6 \mathrm{~g} \mathrm{~L}^{-1}: 0.5 \mathrm{~mm}$ brass orifice, from $0-120 \mathrm{~s}$ and $0.5 \mathrm{~mm}$ printed orifice, from $120-240 \mathrm{~s}$.

The front inlet to PROTeGE is a $6.35 \mathrm{~mm}(0.25 \mathrm{in})$ barbed tube to connect to a pressurized airflow. The inlet is endcapped by the orifice. Directly following, and perpendicularly oriented to the orifice, is the liquid feed $3.18 \mathrm{~mm}$ ( $0.125 \mathrm{in}$ ) inlet to the dispersible solution. Excess liquid from the nebulizing process exits the chamber through a $6.35 \mathrm{~mm}$ outlet at the bottom, dripping directly back into the feed bottle. Aqueous particles exit the chamber through the $9.53 \mathrm{~mm}$ ( 0.375 in) aerosol outlet at the top. The overall dimensions of PROTeGE are $17 \times 45 \times 65 \mathrm{~mm}$ (width, depth, height). Designed CAD files were converted to style files (.stl) to be readable by the 3D printer software (PreForm, Formlabs Inc.).

\subsection{Manufacturing}

The manufacturing and post-processing of the parts was performed as described by Roesch et al. (2017) using the same 3D printer software, clear photopolymer resin (FLGPCL02, Formlabs Inc.) and 3D SLA printer (Form 2, Formlabs Inc.). Modifications were made to the dimensions of the default contact points of the printing scaffolding; in this study scaffolding was reduced to $0.45 \mathrm{~mm}$ due to the overall smaller geometry of PROTeGE (i.e., lower mass needing to be supported). Using a resolution of $100 \mu \mathrm{m}$, eight complete PROTeGEs can be printed on the build surface at the same time, taking $\sim 8 \mathrm{~h}$.

A custom UV box was used to post-cure the printed parts. Inside the box, the printed parts were placed on a slowmoving turntable to be illuminated equally from all sides by 28 high-power LEDs emitting at $405 \mathrm{~nm}$. It should be noted that the curing time depends on the size and wall thickness of the printed part; $1 \mathrm{~h}$ per millimeter of wall thickness is suggested. The post-curing time for PROTeGE was $\sim 1 \mathrm{~h}$. For more detailed information see the manufacturing section in Roesch et al. (2017). The cost to produce one PROTeGE is around USD $\sim 2.50$ depending on the type of resin and the percentage of scaffolding used. The commercial brass nozzle costs < USD 10, so a total PROTeGE costs under USD 15. For users with no access to a 3D printer, it is also possible to upload the stl file for PROTeGE (provided at https://www.thingiverse.com/thing:4444498, last access: 14 December 2020) to an online print service. Pictures of PROTeGE and post-processing details for the instrument are also provided in the data repository as well as the Supplement to this study.

\subsection{Experimental setup}

A schematic of the experimental setup including the relevant flow rates used in this study is shown in Fig. 2. Dry, filtered, pressurized air was used as the carrier gas. The input flow rate of $1.7 \mathrm{~L} \mathrm{~min}^{-1}$ (at $35 \mathrm{psi}$ ) into PROTeGE was controlled by a rotameter (MR3A, Omega Engineering). A high-velocity jet is created by the expansion of the pressurized air through the orifice. As a result, the pressure behind the orifice drops, the liquid is pulled upward from the feed bottle and the highvelocity jet disperses the liquid solution into droplets. Large droplets that are unable to follow the streamlines through the aerosol outlet are removed by impaction at the curved wall; these drip back as excess liquid into the feed bottle through a drain outlet at the bottom of PROTeGE. For these experiments, the droplets from the aerosol outlet were subsequently dried using a silica gel drier. Downstream, the flow of residuals (remaining solid cores of the droplets) was split into two flows. The first is sent to the OPS, to determine particle number size distributions (PNSDs) in the size range of 0.3 to $10 \mu \mathrm{m}$, and the remainder through a filter (IDN-4G, Parker) open to lab. Unless otherwise noted, all experiments presented here were performed using the brass nozzle with a 
$0.3 \mathrm{~mm}$ orifice and the previously stated pressures and flow rates.

\section{Results}

In this study three types of experiments were conducted: (1) an aerosol production experiment using four different sizes of PSL particles, ranging from 0.75 to $5.0 \mu \mathrm{m}$; (2) an application experiment where different concentrated ammonium sulfate solutions were dispersed and monitored over time with the OPS and for the $0.6 \mathrm{~g} \mathrm{~L}^{-1}$ also with the SEMS; and (3) a comparison experiment on the performance of a printed $0.5 \mathrm{~mm}$ orifice versus a $0.5 \mathrm{~mm}$ commercial brass orifice using the same ammonium sulfate solution. For all experiments the PNSDs of the droplet residuals (i.e., after drying) were measured with the OPS.

Prior to each experiment, PROTeGE was immersed in a jar with destilled de-ionized (DDI) $18.2 \mathrm{M} \Omega \cdot \mathrm{cm}$ Millipore water and sonicated for $10 \mathrm{~min}$ in an ultrasonic bath to ensure clean inner surfaces. Afterwards, PROTeGE was dried using pressurized nitrogen and connected to the setup. Each of the four samples was prepared in a separate $100 \mathrm{~mL}$ glass bottle, using $80 \mathrm{~mL}$ of DDI water plus multiple drops of the respective PSL solution $(0.75,1.5,2.0,5.0 \mu \mathrm{m})$. The generated number concentration of PSL particles strongly depends on the concentration of the prepared PSL sample. Therefore, the higher the concentration of the solution, the higher the generated particle number concentration. A time series measurement of $420 \mathrm{~s}$ was performed for each of the four PSL samples. The obtained PNSDs showed particle number concentrations of $\sim 10000 \mathrm{~cm}^{-3}$ for $0.75 \mu \mathrm{m}$ PSL particles, $\sim 1000 \mathrm{~cm}^{-3}$ for $1.5 \mu \mathrm{m}$ PSL particles, $\sim 800 \mathrm{~cm}^{-3}$ for $2.0 \mu \mathrm{m}$ PSL particles and $\sim 100 \mathrm{~cm}^{-3}$ for $5.0 \mu \mathrm{m}$ PSL particles (Fig. 3). All four investigated PSL samples showed a narrow PNSD except the $5.0 \mu \mathrm{m}$ PSL sample where a fraction of sub-micrometer particles was detected (Fig. 3d). This fraction of particles likely originates from the solution matrix in which the PSL particles are suspended. Overall the generated PNSDs were stable over their measured period of time while only the $1.5 \mu \mathrm{m}$ PSL sample showed a slight decrease. These data show that the curved design of the chamber enables PROTeGE to disperse PSL particles with a diameter up to $5.0 \mu \mathrm{m}$.

In addition to the PSL measurements, ammonium sulfate experiments with different solution concentrations $(0.1,0.6$, $\left.5.0 \mathrm{~g} \mathrm{~L}^{-1}\right)$ and an experiment to determine the performance of the printed $0.5 \mathrm{~mm}$ orifice versus the $0.5 \mathrm{~mm}$ brass orifice using the same ammonium sulfate solution of $0.6 \mathrm{~g} \mathrm{~L}^{-1}$ was conducted. The three solutions were again prepared in separate $100 \mathrm{~mL}$ glass bottles using DDI $18.2 \mathrm{M} \Omega \cdot \mathrm{cm}$ Millipore water. The cleaning procedure of PROTeGE was identical to the one described above for the PSL experiments.

For the lowest concentration of aqueous ammonium sulfate solution $\left(0.1 \mathrm{~g} \mathrm{~L}^{-1}\right)$ the maximum particle number con- centration of $\sim 14000 \mathrm{~cm}^{-3}$ was observed in the $0.3 \mu \mathrm{m}$ bin of the OPS (Fig. 4a). The overall width of the generated PNSDs ranged from 0.3 up to $0.6 \mu \mathrm{m}$. Compared to the more highly concentrated solutions of 0.6 and $5.0 \mathrm{~g} \mathrm{~L}^{-1}$, this is rather narrow. Dispersing the $0.6 \mathrm{~g} \mathrm{~L}^{-1}$ solution of ammonium sulfate generated PNSDs in the range of 0.3 up to $1.5 \mu \mathrm{m}$ with a maximum particle number concentration of $\sim 8200 \mathrm{~cm}^{-3}$ in the $0.5 \mu \mathrm{m}$ detection bin of the OPS (Fig. 4b). For the highest concentration of $5.0 \mathrm{~g} \mathrm{~L}^{-1}$ the generated PNSDs ranged from 1.0 to $2.4 \mu \mathrm{m}$ with a maximum particle number concentration of $\sim 7600 \mathrm{~cm}^{-3}$ (Fig. 4c).

For the $0.6 \mathrm{~g} \mathrm{~L}^{-1}$ solution an additional experiment using the SEMS instrument was performed. The size range was scanned from 10 to $1000 \mathrm{~nm}$ with a resolution of 60 bins and a sampling rate of $1 \mathrm{~s}$ per bin. The maximum particle number concentration was found at $\sim 50 \mathrm{~nm}$ with $\sim 40000 \mathrm{~cm}^{-3}$. The average PNSD for a $420 \mathrm{~s}$ sampling period is shown in Fig. 4d. During the experiment the generated size distributions did not change over time. Combining the obtained size distributions from SEMS and OPS shows that PROTeGE is capable of generating particles as small as $10 \mathrm{~nm}$ up to $2.4 \mu \mathrm{m}$ based on the dispersed ammonium sulfate solution. The higher the concentration of the solution, the larger the generated particles. Also, compositions that were used in this study may deviate from stock solutions.

Overall, the generated particle number concentrations for the different tested ammonium sulfate solutions are high enough $\left(>1000 \mathrm{~cm}^{-3}\right)$ to operate particle size selection instruments downstream of PROTeGE, e.g., a differential mobility analyzer (DMA), assuming $\sim 10 \%$ of the introduced particles are selected as monodisperse aerosol particles.

In order to investigate the performance of an integrally printed $0.5 \mathrm{~mm}$ orifice versus the commercial brass nozzle the same $0.6 \mathrm{~g} \mathrm{~L}^{-1}$ ammonium sulfate solution was used. Visual observations of the printed $0.5 \mathrm{~mm}$ orifice showed that there were sometimes imperfections and asymmetries in the roundness of the printed orifice. It was therefore necessary to post-drill the printed orifice with a $0.5 \mathrm{~mm}$ bit by hand, which was done for the PROTeGE used in the experiment described here. The generated particle number concentration with the printed orifice was $\sim 4500 \mathrm{~cm}^{-3}$ versus $\sim 2400 \mathrm{~cm}^{-3}$ for the brass nozzle with minimal difference in PNSD shape. The printed nozzle exhibited a broader shoulder from 0.3 to $0.5 \mu \mathrm{m}$ with higher particle number concentrations than the brass nozzle. The latter showed a decline with the highest particle number concentration at $0.3 \mu \mathrm{m}$ leveling out to $1.0 \mu \mathrm{m}$. Overall, the width of both PNSDs ranged from 0.3 to $1.0 \mu \mathrm{m}$ (Fig. 5).

\section{Conclusions}

In this study, we described the design and the performance of a low-cost particle generator - PROTeGE. The experiments presented here show the PROTeGE capability of generating 
four different sizes of PSL particles between 0.75 and $5.0 \mu \mathrm{m}$ with resulting particle number concentrations between 100 and $\sim 10000 \mathrm{~cm}^{-3}$. This enables PROTeGE to be used as a simple and cost-effective particle generation unit for calibration purposes. In addition, we show the results of experiments using different concentrations of ammonium sulfate solutions. The generated PNSDs ranged from $10 \mathrm{~nm}$ up to $2.4 \mu \mathrm{m}$, based on the dispersed solution, with stable output concentrations demonstrating that particle size selection instruments can be used downstream of PROTeGE. Finally, we compared the performance of a commercially machined brass $0.5 \mathrm{~mm}$ orifice to a $3 \mathrm{D}$ printed $0.5 \mathrm{~mm}$ orifice. Both nozzles showed PNSDs ranging from 0.3 to $1.0 \mu \mathrm{m}$ with a broader shoulder for the printed nozzle between 0.3 and $0.5 \mu \mathrm{m}$ compared to the brass orifice. Also, the total particle number concentration generated with the printed orifice was almost 2 times higher than the total particle number concentration generated with the brass orifice.

Due to the low cost of PROTeGE ( USD 15, material costs) multiple generators can be used in parallel to reduce experimental time while running more samples. If one is in doubt about the usage of certain liquids with PROTeGE, please refer to the material safety data sheet (MSDS) of the resin or contact the manufacturer for details about chemicals having dissolving properties on SLA 3D printed materials. Electro-plating the 3D printed generator will give it metallike properties for better resistance against chemical attack.

Data availability. The .stl files for PROTeGE are available at https: //www.thingiverse.com/thing:4444498 (last access: 14 December 2020; Markerbot Industries, 2020) and also as the Supplement to this study.

Supplement. The supplement related to this article is available online at: https://doi.org/10.5194/amt-13-6807-2020-supplement.

Author contributions. MR and DJC both contributed equally to the manuscript. The experiments were conducted by MR.

Competing interests. The authors declare that they have no conflict of interest.
Review statement. This paper was edited by Pierre Herckes and reviewed by three anonymous referees.

\section{References}

Eerikainen, H., Watanabe, W., Kauppinen, E. I., and Ahonen, P. P: Aerosol flow reactor method for synthesis of drug nanoparticles, Euro. J. Pharma. Biopharma., 55, 357-360, 2003.

Kong, X., Wolf, M., Roesch, M., Thomson, E. S., Bartles-Rausch, T., Alpert, P. A., Ammann, M., Prisle, N. L., and Cziczo, D. J.: A continuous flow diffusion chamber study of sea salt particles acting as cloud nuclei: deliquescence and ice nucleation, Tellus B, 70, 1-11, https://doi.org/10.1080/16000889.2018.1463806, 2018.

Liu, B. Y. H. and Lee, K. W.: An Aerosol Generator of High Stability, Am. Ind. Hyg. Assoc. J., 36, 861-865, 1975.

Markerbot Industries, LLC, Thingiverse, available at: https://www. thingiverse.com/thing:4444498, last access: 14 December 2020.

May, K. R.: The Collusion Nebulizer: Description, Performance and Application, J. Aero. Sci., 4, 235-243, 1973.

Reisner, C., Katial, R. K., Bartelson, B. B., Buchmeir, A., Rosenwasser, L. J., and Nelson, H. S.: Characterization of aerosol output from various nebulizer/compressor combinations, A. All. Asth. Immun., 86, 566-574, 2001.

Roesch, M., Roesch, C., and Cziczo, D. J.: Dry particle generation with a 3-D printed fluidized bed generator, Atmos. Meas. Tech., 10, 1999-2007, https://doi.org/10.5194/amt-101999-2017, 2017.

Swiderska-Kowalczyk, M., Gomez, F. J., and Martin, M.: Particle generation methods applied in large-scale experiments on aerosol behavior and source term studies, Inform. Tech. Cie., 819, 1-112, 1997.

Wex, H., Augustin-Bauditz, S., Boose, Y., Budke, C., Curtius, J., Diehl, K., Dreyer, A., Frank, F., Hartmann, S., Hiranuma, N., Jantsch, E., Kanji, Z. A., Kiselev, A., Koop, T., Möhler, O., Niedermeier, D., Nillius, B., Rösch, M., Rose, D., Schmidt, C., Steinke, I., and Stratmann, F.: Intercomparing different devices for the investigation of ice nucleating particles using Sno$\max { }^{\circledR}$ as test substance, Atmos. Chem. Phys., 15, 1463-1485, https://doi.org/10.5194/acp-15-1463-2015, 2015.

Wang, J., Shilling, J. E., Liu, J., Zelenyuk, A., Bell, D. M., Petters, M. D., Thalman, R., Mei, F., Zaveri, R. A., and Zheng, G.: Cloud droplet activation of secondary organic aerosol is mainly controlled by molecular weight, not water solubility, Atmos. Chem. Phys., 19, 941-954, https://doi.org/10.5194/acp-19-9412019, 2019. 